\title{
UN NUEVO ASEDIO A LA OBRA DE JUAN RULFO
}

\author{
POR
}

\author{
WARREN L. MEINHARDT \\ University of Southern Illinois
}

Estos infructuosos aldabonazos a la puerta del rey .... -Jorge Ruffinelli

Suele engañarnos la primera impresión. Y tal es, desgraciadamente, el caso de la edición más reciente de la obra completa de Juan Rulfo. ${ }^{1}$

Este nuevo asedio a la obra de Rulfo es un libro que parece destinado a causar múltiples dolores de cabeza para críticos, estudiosos y bibliógrafos. Se anunció en la prensa más de un año atrás con el título de Juan Rulfo; obra completa, Colección Archivos, Número 18, dirección de Carlos Montemayor. Sin embargo, no apareció hasta fines de 1992. Y el volumen publicado lleva el nombre de otro director, otro número en la serie y otro título. Hasta la fecha exacta de su publicación es problemática. Al reverso de la portada, la ficha de la Biblioteca Nacional de Madrid registra el año de 1991, pero el colofón reza 1992. Con tales confusiones no nos parece muy arriesgado vaticinar numerosos problemas para los que quieran fijar los datos bibliográficos de esta edición y su sombra.

Se trata de un volumen de regular tamaño con un dibujo de Rufino Tamayo en la cubierta, el mismo que se repite en la tapa de cartulina. En la mano, al sopesarlo, el tomo parece ser macizo, bien confeccionado. Las páginas son de papel muy blanco y de buena calidad -si bien un tanto translúcido, pues la impresión del reverso de cada hoja se deja ver desde el recto. El tipo de imprenta varía desde un tamaño bastante legible en el caso de los textos rulfianos, hasta tan chico en el caso de las citas textuales y las notas, que al lector medianamente miope le hará falta una lupa para leerlas. Así es que nuestra primera impresión, francamente positiva, se atenúa al manejar el tomo.

$\mathrm{Y}$ al examinar su contenido.

El libro se divide en ocho secciones: I. Introducción; II. El texto; III. Cronología; IV. Historia del texto; V. Lecturas del texto; VI. Dossier; VII. Bibliografía; y VIII. Filmografía de Juan Rulfo. Veamos por partes.

\footnotetext{
${ }^{1}$ Juan Rulfo; toda la obra. Edición crítica. Claude Fell, coordinador. Espana: Colección Archivos 17, 1991 (colofón 1992) xxxix. Con retrato y autógrafo del autor.
} 


\section{INTRODUCCIÓN}

En esta sección se reproducen como "Liminar" del volumen los versos de José Emilio Pacheco, “¿Qué tierra es ésta?” (xvii-xx). ${ }^{2}$ Al "Liminar” le siguen la "Introducción del Coordinador" y una "Nota filológica preliminar" de Sergio López Mena.

En su "Introducción" (xxi-xxx), el Coordinador primero explica los propósitos que guían la edición de El Llano en llamas y Pedro Páramo: 1) Cotejar manuscritos y versiones impresas para demostrar que los textos son del autory no ajenos; 2) señalar las modificaciones introducidas por el propio Rulfo en esos textos; 3) determinar el significado de dichas modificaciones (xxiii); y 4) establecer el texto definitivo de los relatos y la novela, tarea al cargo de Sergio López Mena (xxiv). ${ }^{3}$ Fell pasa luego a explicar por qué no es exacto el título de la presente edición: No se trata de "toda la obra" de Rulfo, sino de un conjunto de textos no reunidos antes. ${ }^{4}$ Acto seguido el Coordinador detalla las obras incluidas y concluye pasando revista a los doce estudios sobre Rulfo y su obra agrupados en las secciones IV y $\mathrm{V}$ del volumen.

A nuestro juicio, el verdadero paladín de esta empresa es Sergio López Mena, el encargado de establecer el texto definitivo de los relatos de El Llano en llamas y de la novela Pedro Páramo. López Mena da cuenta modestamente de su nada modesta tarea en su "Nota filológica preliminar" (xxxi-xxxix), el aporte tal vez más significativo del presente volumen, y aun de la crítica rulfiana. El filólogo explica su plan de trabajo y nos informa acerca de los diferentes momentos que conforman el proceso de creación y de publicación de la obra de Rulfo. De paso, nos brinda la imagen de un artista dedicado tesoneramente a castigar la forma y la expresividad de sus páginas. Para quien desee conocer la historia de los textos rulfianos, la lectura de esta nota es el indispensable punto de partida.

\footnotetext{
${ }^{2}$ Se trata de un poema-collage construido con palabras textuales de Juan Rulfo para evocar paisajes, gente y ambiente del mundo rulfiano. No se indica la procedencia de los versos, como se hace en el caso de otros textos editados anteriormente y reproducidos en la presente edición. Estos versos aparecieron antes en Juan Rulfo; homenaje nacional (México, 1980) 45-48; 2a ed., Inframundo; el México de Juan Rulfo (Hanover, NH, 1983) 39-40; inglés: "What land is this?" Inframundo; the Mexico of Juan Rulfo (Hanover, NH, 1983) 3-5. Estos datos bibliográficos los entresacamos de la extensa bibliografia comentada que sobre Juan Rulfo venimos preparando en estos días y que esperamos entregar a la imprenta en un futuro no muy lejano.

${ }^{3}$ Se toma como texto base la edición del Fondo de Cultura Económica de Obras (México, 1987). López Mena explica los criterios de esta selección en su "Nota filológica preliminar" (xxxi-xxxix) que comentamos seguidamente en nuestra nota.

${ }^{4}$ En nota al pie de la página xxiv, Fell aclara que del presente conjunto, ciertos textos de Juan Rulfo hubieron de ser excluidos ante la negativa de los derechohabientes de autorizar su publicación. Los textos omitidos incluyen: "A manera de presentación," "Después de la muerte," "Mi padre," "Marcelo Quiroga Santa Cruz," "Daisy Ascher," "Carta de México," "Cumple treinta años Pedro Páramo" y "Tres cartas a Clara." Este último texto se cita de modo diferente en la Bibliografia ("'Dos' cartas a Clara," 896). ¿Un descuido de parte de los editores? Ignoramos la razón de la mencionada negativa, pero nos parece tal vez menos lamentable que injustificable.
} 


\section{El TEXTo}

Gracias a la concienzuda labor de López Mena, tenemos ya una edición crítica tanto de los relatos que integran El Llano en llamas ${ }^{5}$ como de la novela Pedro Páramo. El filólogo presenta en esta sección los textos definitivos con todas las variantes detalladas en notas al margen y a pie de página. Dichos textos vuelven obsoletas las ediciones anteriores de los dos libros básicos de Juan Rulfo.

Bajo el rubro de "Otras letras" en esta misma sección, se incluyen algunas prosas menores de Rulfo, agrupadas en tres incisos: "Relatos y textos autobiográficos"; "Textos para cine"; y "Ensayos, discursos, conferencias y prólogos". 6

\section{Cronología}

La "Cronología" se presenta en un cuadro a tres columnas y ofrece datos notables relacionados con la vida y obra de Juan Rulfo y con la historia de México y de América Latina? $^{\text {? }}$

\section{Historia deL TEXTo}

Esta sección incluye cuatro ensayos. En "La ficción de Juan Rulfo; nuevas formas del decir," Norma Klahn analiza la (con)fusión de narradores y personajes y el lenguaje literario nuevo que finge ser oral. Walter Mignolo examina la ficcionalización de la oralidad y la escritura y su relación con las culturas nativas en "Escribir la oralidad; la obra de Juan Rulfo en el contexto de las literaturas del 'Tercer Mundo'." Jorge Ruffinelli, en "La leyenda de Rulfo; cómo se construye el escritor desde el momento en que deja de serlo," rechaza las pretensiones de ciertos mentores del autor que quisieron dar a entender que habían reescrito en parte su novela; y de paso aboga por una interpretación mítica de la obra rulfiana dentro del contexto mexicano. El último trabajo de esta sección es un minucioso examen de las

\footnotetext{
'López Mena retoma la grafia "Llano" con mayúscula, señalando que así figura en el manuscrito original por aludir a un lugar preciso en la región donde Juan Rulfo situó su obra. Curiosamente, no se respeta esta grafia ni en el "Indice general" (xi) ni en la carátula de la colección incluida en esta edición (página 3). ¿Otro descuido de los editores del presente volumen?

${ }^{6}$ Relatos y textos autobiográficos: "Un pedazo de noche" y "La vida no es muy seria en sus cosas"; Textos para cine: "El gallo de oro," "La fórmula secreta" y "El despojo"; Ensayos, discursos, conferencias y prólogos: "Situación actual de la novela contemporánea"; "José Gorostiza"; "El desafío de la creación"; "Machado de Assis"; "Nuño de Guzmán, el muy magnífico señor de Jalisco"; "Sahagún y su significado histórico"; "Los chinantecos de Oaxaca"; "México y los mexicanos"; "Muchas gracias"; "iBuenos días, España!" Como se ve, esta breve selección es apenas un muestrario de la obra menor (crítica, ensayística, etc.) del autor.

${ }^{7}$ Sin ser idéntica a las cronologías incluidas en la Obra completa preparada por Jorge Ruffinelli (Venezuela, 1977) 213-293 y en la edición cubana de El Llano en llamas / Pedro Páramo (La Habana, 1968) [283-284, sin enum.], se retoma aquí el mismo esquema. No se indica ni procedencia ni autor para la presente cronología.
} 
diversas aproximaciones a la narrativa rulfiana, el cual presenta con laboriosa documentación una perspectiva casi total de lo que se ha escrito sobre Rulfo. El título: "Vista panorámica; la obra de Juan Rulfo en el tiempo y en el espacio," de Gerald Martin.

\section{LeCTURAS DEL TEXTo}

Son ocho artículos que corren la gama de enfoques e interpretaciones. José Carlos González Boixo nos ofrece una "Lectura temática de la obra de Juan Rulfo," destacando la violencia, la desolación, el aislamiento y la muerte. ${ }^{8}$ Evodio Escalante examina en "Texto histórico y texto social en la obra de Juan Rulfo" el mundo rural y el impacto de la Revolución. Yvette Jiménez de Báez interpreta la alegoría y los símbolos en los textos y la inversión del modelo utópico en "Historia y sentido en la obra de Juan Rulfo." José Pascual Buxó estudia en "Juan Rulfo; los laberintos de la memoria" los monólogos paradójicamente interiorizados y comunicativos de los personajes rulfianos. " "La seducción de los fantasmas en la obra de Juan Rulfo" es el título del trabajo de Florence Olivier, quien analiza el juego de la seducción fantasmal que se desarrolla a tres niveles (simple, intermedio, complejo) y que produce los efectos mágicos discernibles en Pedro Páramo. Mónica Mansour ofrece otro estudio sobre la memoria, esa dolorosa fuente de recuerdos y ecos que se entretejen entre relato y novela, novela y relato. Título: "El discurso de la memoria." En "Miradas sobre Pedro Páramo y la Divina commedia," Hugo RodríguezAlcalá descubre puntos de contacto entre Comala y el Sexto Círculo dantesco, donde el tiempo se anula y se eterniza el dolor. ${ }^{10} \mathrm{Y}$ finalmente, Milagros Ezquerro interviene en la polémica sobre el género de "El gallo de oro" sosteniendo que este guión de cine es en realidad una novela. Su trabajo tiene por título, "El gallo de oro o el texto enterrado."

\section{DOSSIER ${ }^{11}$}

Lo primero que se nota al abrir esta sección del volumen es el reducido tipo de imprenta del texto. La letra chica no presentará problemas, sin embargo, para el lector prevenido que se arme de un vidrio.

\footnotetext{
${ }^{8}$ No se indica la procedencia de los trabajos agrupados en las secciones IV y V. El de González Boixo es una refundición del Cap. III de su libro Claves narrativas de Juan Rulfo (León España, 1980) 53 148. 2a edición (1983, col. 1984).

${ }^{9}$ Este trabajo de Buxó se editó primero en Universidad de México 43 (diciembre 1988) 34-38; apareció después una versión abreviada en Juan Rulfo; un mosaico crítico (México, 1988) 179-187. ${ }^{10}$ El estudio de Rodríguez-Alcalá es una ampliación de los conceptos del crítico insertos en el trabajo publicado con Jean-Pierre Barricelli, "Dante and Rulfo; beyond time and through eternity," Hispanic Journal 5, 1 (Fall 1983) 7-27.

"López Mena escribe en la página xxxix: "En el dossier que acompaña esta edición crítica presento, agrupados por su naturaleza, los textos de Rulfo que conservamos aparte de El Llano en llamas y de Pedro Páramo." Dichos textos no se presentan en el "Dossier", sino en "Otras letras" (Sección II, "El Texto"). ¿Otro descuido más de parte de los editores?
} 
Se recogen aquí veinte trabajos críticos sobre Rulfo y su obra editados anteriormente en otras publicaciones. ${ }^{12}$ Emmanuel Carballo rebate la tesis de lo negativo en Rulfo en "Arreola y Rulfo," fragmento de su reseña de 1954. Carlos Blanco Aguinaga destaca los rasgos distintivos de la obra rulfiana en "Realidad y estilo de Juan Rulfo" (1955), uno de los ensayos más difundidos. En "Rulfo's Pedro Páramo, a Vision of Hope" (1966), Alan $\mathrm{S}$. Bell descubre una nota optimista en la novela. ${ }^{13}$ Julio Ortega propone una lectura mítica en "La novela de Juan Rulfo, summa de arquetipos," arguyendo que Juan Preciado encarna tanto a Moisés como a Telémaco. ${ }^{14}$ "A través de la ventana de la sepultura; Juan Rulfo" (1970) de Joseph Sommers, nos brinda una interpretación poética y mítica de la novela con un estudio de los recursos narrativos. George Ronald Freeman ofrece otro enfoque mítico en "La caída de la gracia, clave arquetípica de Pedro Páramo."15 La "Relectura de Pedro Páramo" (1974) que propone Emir Rodríguez Monegal destaca la estructura simbólica de la novela, mientras que Felipe Garrido hace hincapié en el carácter sociológico de la obra rulfiana. ${ }^{16}$ Jean Franco, en "El viaje al país de los muertos," sintetiza las lecturas mítica y sociológica descubriendo en Juan Preciado la figura del caminante de los infiernos perdido por el sistema capitalista. ${ }^{17}$ Un intento de fijar las bases de una valoración sociológica lo encontramos en el trabajo del crítico chileno, Marcelo Coddou, "Fundamentos para la valoración de la obra de Juan Rulfo (proposiciones para la interpretación y análisis del cuento 'El hombre')" (1971). "Una primera lectura de 'No oyes ladrar los perros' de Juan Rulfo" (1975), ${ }^{18}$ es el penetrante análisis que realiza Ángel Rama de la "monstruosa" imagen

\footnotetext{
${ }^{12}$ Entre los ensayos de crítica que integran esta sección y la anterior no se incluye nada de Luis Leal, omisión que nos parece asombrosa. Leal es el primer biógrafo de Rulfo, uno de los críticos más prolificos de su obra y tal vez el más constantemente lúcido de cuantos se han ocupado del autor jalisciense. A nuestro parecer, no se justifica tal omisión, sobre todo cuando tomamos en cuenta la franca mediocridad de alguno que otro de los ensayos seleccionados. Es otra lamentable falla en la presente edición.

${ }^{13}$ La nota de Bell es el único texto en inglés que recoge el presente volumen.

${ }^{14}$ La nota al pie de la página 723 indica que el texto del trabajo de Ortega procede de su libro $\mathrm{La}$ contemplación y la fiesta (Caracas, 1969) 17-30. Pero en esa edición el título es "Pedro Páramo" a secas. El título citado aquí corresponde a la edición de Joseph Sommers, La narrativa de Juan Rulfo (México, 1974) 76-87.

${ }^{15}$ Según nota al pie de la página 740, el ensayo procede del libro del autor, Paradise and Fall in Rulfo's "Pedro Páramo" (Cuernavaca, 1970) 2, 1-2, 23. Pero estos datos se refieren al original en inglés. La versión castellana (de Joseph Sommers) que se recoge aquí aparece en La narrativa de Juan Rulfo (México, 1974) 67-75. Véase nuestra nota 14.

${ }^{16}$ Aquí no se indica la procedencia del texto de Garrido. Apareció primero como prólogo a la edición de Pedro Páramo y El Llano en llamas de Juan Rulfo (México, 1979) vii-xxviii. Se reimprimió en Para cuando yo me ausente, Juan Rulfo, editor (México, 1983) 13-34.

${ }^{17}$ Según la nota al pie de la página 763, este ensayo se retoma de La casa encantada, libro-fantasma cuya "próxima publicación" Franco viene anunciando desde 1974. Las únicas ediciones que conocemos del presente ensayo son La narrativa de Juan Rulfo (México, 1974) 117-140; y Para cuando yo me ausente (México, 1983) 215-237. Véanse nuestras notas 14 y 16.

${ }^{18}$ Este ensayo apareció primero en el número 12 del volumen 29 de la revista Universidad de México, y no en el número 2, como lo indica la nota al pie de la página 790 de esta edición. El mismo ensayo se recopiló después con el título "Juan Rulfo" en Primeros cuentos de diez maestros latinoamericanos. Selección y lectura crítica đe Ángel Rama (Barcelona, 1975) 203-223. Otra edición: (México, 1977) 219-241.
} 
inicial del viejo padre con el hijo a horcajadas. Gabriel García Márquez confiesa en "Breves nostalgias sobre Juan Rulfo"19 que sólo al conocer las obras del escritor jalisciense —"tan perdurables como las que conocemos de Sófocles" (801) - pudo descubrir por fin el camino hacia Cien años de soledad. En "Los trasterrados de Comala" (1981), Augusto Roa Bastos señala (807) con razones convincentes la posibilidad de explicar Pedro Páramo en el contexto del "trasfondo mítico de la cultura enterrada" -indígena, mexicana- sin necesidad de recurrir a los mitos europeos. En vez del "Ulises de piedra y barro" que propone Carlos Fuentes, el protagonista sería para Roa Bastos "Tzontémoc, el señor del inframundo" de la cosmogonía náhuatl $(805,806)$. De Gordon Brotherston, ${ }^{20}$ se incluye un texto de 1977 en traducción al español (1980). En "Provincia de almas muertas," el crítico inglés destaca la "ira social" de Rulfo y su "Ilamado a cambiar esta situación" $(812,813)$. El trabajo de Elena Poniatowska — cuyo título, “iAy vida, no me mereces! Juan Rulfo, tú pon la cara de disimulo," hace eco de palabras de dos personjes de la novela rulfiana (Eduviges Dyada ${ }^{21}$ y una mujer tapada) - caracteriza así al autor: "Tiene mucho de ánima en pena" (814); y de los mundos de su ficción afirma que "parecen zonas de desastre abatidas por la sequía" (815). ${ }^{22}$ Carlos Fuentes, en base a ingeniosos juegos paronímicos, presenta una lectura mítica de Pedro Páramo en "Rulfo, el tiempo del mito" (1983). ${ }^{23}$ Palabras de Gerardo Trujillo, abogado al servicio de Pedro Páramo, dan título al trabajo de Carlos Monsiváis, "Sí, tampoco los muertos retoñan, desgraciadamente" (1983), donde el autor observa que la ambigüedad de la obra rulfiana obliga a una constante relectura. Martin Lienhard, autor de "El sustrato arcaico en Pedro Páramo; Quetzalcóatl y Tláloc" (1983), propone también una ingeniosa lectura mítica fundamentada en los códices prehispánicos:

\footnotetext{
${ }^{19}$ Según la nota al pie de la página 799, se recoge este trabajo de Inframundo (México, 1980) 23-25. La fecha es incorrecta. Inframundo; el México de Juan Rulfo se editó en 1983 (Hanover, NH) y es la segunda edición de Juan Rulfo; homenaje nacional (México, 1980). Véase nuestra nota 2.

${ }^{20} \mathrm{El}$ apellido del crítico inglés se escribe erróneamente "Brotherson" en el Indice general (xiii) y en el encabezamiento de su ensayo (808). El error aparece también en Juan Rulfo, editor, Para cuando yo me ausente (México, 1983) 203-213, de donde se recoge el texto de Brotherston para esta edición. El ensayo apareció originalmente en inglés ("Province of dead souls; Juan Rulfo") en The Emergence of the Latin American Novel (Cambridge, 1977) 71-80, 146; y en version castellana de Daniel Samper Pizano, "Provincia de almas muertas; Juan Rulfo," en La irrupción de la novela latinoamericana (Bogotá, 1980) 101-111, 198. Los editores de la edición que comentamos parecen ignorar estos detalles.

${ }^{21}$ Véase al respecto el estudio de Domenico Antonio Cusato, "Intorno all'XI frammento di Pedro Páramo." Studi di letteratura ispano-americana 21 (Milano, 1990) 67-75.

${ }^{22}$ Según la nota al pie de la página 814 el texto procede de Inframundo (México: Ediciones del Norte, 1983) 41-52. En esta segunda edición de Juan Rulfo; homenaje nacional (México, 1980), no se precisa el lugar de publicación, pero se sabe que Ediciones del Norte tiene su sede en Hanover, New Hampshire (USA) y no en México. Véase nuestra nota 2.

${ }^{23}$ Fuentes destaca en la novela el proceso del "misterio" que pasa del "mutismo" ("mugido"), a través de la "palabra" ("mito," francés "mot"), a la "nada" ("muerte") y la "reunión con el padre" (827-828, 832-833). Nuestra observación en la nota anterior sobre la procedencia del texto de Poniatowska se hace extensiva al caso de este ensayo de Fuentes y también del trabajo de Carlos Monsiváis que comentamos seguidamente en nuestro texto.
} 
Juan Preciado sería el Quetzalcóatl que viaja por Mictlan/Comala, país de los muertos, para resucitar a los habitantes mediante el discurso narrativo; Pedro Páramo sería el dios de la lluvia, Tláloc, que primero permite florecer un paraíso terrenal, Tlálocan / Comala (en el recuerdo de Dolores Preciado) para traer después la sequía mortal al verse contrariado por sus súbditos. "Estructuras antropológicas en Pedro Páramo" (1988), trabajo de Anthony Stanton, presenta un análisis de la función del mecanismo de sustitución, confusión y transferencia de roles sociales entre los personajes de la novela.

Se cierra esta sección con verdadero broche de oro: "Juan Rulfo examina su narrativa," diálogo burlón que sostuvo el autor mexicano con los estudiantes de la Universidad Central de Venezuela en 1974. Rulfo habla de su Tío Celerino, quien sería el verdadero autor de todos sus cuentos; de Susana San Juan, el Boom, la literatura nórdica, el indigenismo en su obra, la interpretación mitológica de Pedro Páramo y las películas sacadas de sus libros. Todo el diálogo es una enorme tomadura de pelo, pues Rulfo reconoció en entrevistas posteriores que "estaba en vena" y no hacía más que inventar mentiras. ${ }^{24}$

\section{BiBLIOGRAFÍA}

El título de esta sección, que estuvo a cargo de la bibliógrafa mexicana Aurora M. Ocampo, es "Una contribución a la bibliografía de y sobre Juan Rulfo."25 Consta de cinco apartados: 1. "Libros de Juan Rulfo ..."; 2. "Hemerografía de Juan Rulfo ..."; 3. "Homenajes"; 4. "Bibliografias de y sobre Juan Rulfo"; y 5. "Referencias, en orden alfabético de críticos". Las referencias no llevan comentario ni enumeración.

1. Libros de Juan Rulfo. En este apartado se incluyen "Cuentos"; "Cuentos en antologías"; "Ensayos, prosa y prólogos"; "Novela"; "Novela y cuentos"; "Guiones cine y teatro"; "Obras completas"; y "Fotografía".

Las cuatro colecciones de relatos rulfianos se anotan en trece fichas, que incluyen algunas reimpresiones de El Llano en llamas. Catorce cuentos antologados se registran en veintisiete fichas (incluso el fragmento de novela titulado "Un cuento"). Cinco colaboraciones de Rulfo en libros ajenos se incluyen en el inciso "Ensayos, prosa y prólogos". Dos fragmentos de Pedro Páramo con ediciones y reimpresiones de la novela comprenden las diez fichas del inciso "Novela". Las ediciones de conjunto de El Llano en llamas y Pedro Páramo, incluso dos que traen sólo fragmentos de la novela, se detallan en "Novela y cuentos". El inciso "Guiones cine y teatro" contiene ocho fichas, incluso dos ediciones de El gallo de oro y otros textos para cine que contiene la "Filmografia" de Jorge Ayala Blanco. El inciso "Obras completas" registra las ediciones de Jorge Ruffinelli (1977) y del Fondo

\footnotetext{
${ }^{24}$ Véase al respecto Juan E. González, "Entrevista con Juan Rulfo," Nueva estafeta 9-10 (Madrid, agosto-septiembre 1979) 79-86; también, Revista de occidente 9 (Madrid, octubre-diciembre 1981) 105-114. Y Ernesto González Bermejo, "La literatura es una mentira que dice la verdad; una conversación con Juan Rulfo," Universidad de México 34, 1 (septiembre 1979) 4-8.

${ }^{25} \mathrm{El}$ material procede de las recopilaciones del Centro de Estudios Literarios del Instituto de Investigaciones Filológicas y servirá para la elaboración de la ficha de Juan Rulfo en la nueva edición del Diccionario de escritores mexicanos, de próxima publicación. Ya se editó el primer tomo de esta nueva edición del Diccionario.
} 
de Cultura Económica (1987). Dos ediciones de la obra fotográfica de Juan Rulfo se anotan en el inciso "Fotografia". ${ }^{26}$

2. Hemerografia de Juan Rulfo. Cuatro son los incisos de este apartado: "Cuentos"; "Ensayos"; "Novelas (fragmentos)"; y "Poesías". Aquí unas cuarenta y ocho fichas registran veintiocho relatos aparecidos en diversas publicaciones periódicas. Con sólo un par de excepciones, todas ellas son mexicanas. ${ }^{27}$ Una selección de treinta prosas ensayísticas de Rulfo - apuntes, notas, discursos, testimonios, diálogos- se anotan en treinta y seis fichas. ${ }^{28}$ Siete fragmentos, ora de Pedro Páramo, ora de una de las novelas abortadas, se registran en trece fichas. Y si hay lectores que ignoren que Rulfo también hizo versos, podrán formarse una idea de sus dotes de poeta leyendo los dos poemas detallados en este inciso — del cual se excluye el "poema para cine" (Felipe Garrido) titulado "La fórmula secreta."

${ }^{26}$ Las erratas y omisiones más notables en este apartado de la "Bibliografia" son las siguientes: "Cuentos" — no se incluyen ni la Edición de Carlos Blanco Aguinaga de El Llano en llamas (Madrid, 1985); ni Espejo de escritores (Hanover, NH, 1985), dos cassettes: "Video / Audio" (Juan Rulfo lee "Luvina" y fragmentos de $P P$ ); "Novela y cuentos"- no se incluye "Juan Rulfo; a kind of silence," Faces, mirrors, masks; twentieth-century Latin American fiction (Washington, D.C., ¿1985?), N.P.R, Program 12, Un cassette: "Audio" ("Dramatizations from his famous novel, Pedro Páramo"); la fecha correcta de laedición de conjunto de $L L$ y $P P$ por Casa de las Américas (La Habana) es 1968 y no 1969; Antología personal: Se omiten las ediciones de Biblioteca Era (México, 1988) y de Alianza (Madrid, 1988); y "Fotografia": El título Inframundo; el México de Juan Rulfo y la "Introducción" de Frank Janney no corresponden a la primera edición sino a la segunda (Hanover, NH, 1983). El título correcto de la primera edición es Juan Rulfo; homenaje nacional y José Bremer firma la "Presentación" (México, 1980). Véase nuestra nota 2.

${ }^{27}$ En este lugar hemos de destacar la inclusión en la "Bibliografía" (895) de una ficha errónea que viene repitiéndose rutinariamente desde que la puso en circulación Luis Harss en 1967: "La vida no es muy seria en sus cosas," Pan, Guadalajara, Jal., 1942. La revista Pan no existía en 1942. La primera aparición del relato en cuestión fue en América en 1945. Véanse Luis Leal, Juan Rulfo (Boston, 1983) 106 (n. 6); y José Luis Martínez, Literatura mexicana siglo XX. Segunda parte, guías bibliográficas (México, 1950) 167. También se incluye aquí, erróneamente a nuestro parecer, el fragmento de la novela abortada "Una estrella junto a la luna" titulado "Un cuento de Juan Rulfo." Celebramos la inclusión de dos traducciones de relatos rulfianos —una al francés y otra al idioma chontal- pero lamentamos observar que se omite toda referencia a las numerosas versiones de la obra rulfiana que se han editado en unas veintitrés lenguas y que dan idea de la fama verdaderamente universal del autor jalisciense. Consultando la bibliografia de Aurora M. Ocampo, uno podría pensar que Rulfo no se conoce muy bien fuera de México. Advertimos que nuestra bibliografía, mencionada en la nota 2, traerá una amplia sección dedicada a las traducciones a otros idiomas de la obra de Rulfo.

${ }^{28}$ Observamos que en más de una ocasión, se repite una misma ficha en diferentes apartados de la "Bibliografia". Por ejemplo, el trabajo rulfiano titulado "Nuño de Guzmán, el muy magnifico señor de Jalisco" se incluye tanto en este inciso "Ensayos" como en el anterior, "Libros de Juan Rulfo". Semejante repetición de fichas ocurre también en el caso de "Un cuento" que se registra ya como cuento (895), ya como fragmento de novela (896). A veces es difícil explicarnos el criterio seguido en la clasificación de las fichas. Por ejemplo, el texto de Juan Rulfo editado en Los narradores ante el público (México, 1966) 21-26, se incluye aquí entre los Libros de Juan Rulfo (893), mientras que "Juan Rulfo examina su narrativa," Escritura; teoría y crítica literarias 1, 2 (Caracas, julio-diciembre 1976) 305-317, se clasifica como artículo hemerográfico, a pesar de que se trata en ambos casos de la colaboración de Rulfo en un volumen preparado por otros. 
3. Homenajes. El criterio aquí es muy amplio, pues se admiten tanto nutridas colecciones de trabajos de crítica literaria - auténticos homenajes- como meras noticias de libros y necrologías. El título "La muerte de JR," por ejemplo, engrosa el inciso con unas veintiocho entradas sin firma, todas recogidas en publicaciones periódicas mexicanas. De la prensa latinoamericana y extranjera, nada. ${ }^{29}$

4. Bibliografias de y sobre Juan Rulfo. Un caso semejante presenta este apartado. La autora incluye algunas de las principales bibliografías - Ramírez, Lioret, Foster, Juzyn y González Boixo $0^{30}$ - entre las once referencias, pero las restantes son meras listas de obras citadas que acompañan trabajos de crítica. Por ejemplo, la "Bibliografia" - y no "Bibliografía crítica" como reza la ficha aquí (898)- que incluye Ricardo Estrada al final de su estudio de "Los indicios de Pedro Páramo." La lista bibliográfica de Estrada contiene apenas tres títulos, todos de Rulfo: "Un cuento" y sendas ediciones de El Llano en llamas y Pedro Páramo. ${ }^{31}$ No cuestionamos la legitimidad de recoger este tipo de referencias bibliográficas, sino el criterio que permite incluir ésta y no otras (tal vez mejores) de la misma índole que aparecen a centenares en nuestras revistas literarias. ${ }^{32}$

5. Referencias. En este último apartado de la bibliografía, se recogen aproximadamente 1433 entradas en orden alfabético por el apellido de los 718 autores. De éstos, el más prolífico es "Anónimo," quien contribuye un 20\% de los títulos. El 80\% de las 1433

\footnotetext{
${ }^{29}$ Dos verdaderos homenajes que se le olvidaron a la encargada de esta bibliografía: Rulfo en llamas, la edición 1981; 2a edición corregida y aumentada (Naucalpan, 1988). (A instancias del propio Juan Rulfo, se almacenó la primera edición y por lo visto, no se dio al público); y Homenaje a Juan Rulfo, recopilación, revisión de textos y notas, Dante Medina (Guadalajara, 1989).

${ }^{30}$ Ocampo escribe mal los nombres de E. Kent Lioret - pone "Liorent"-y David William Foster pone "Williams" por el segundo nombre y lo toma por apellido: "Williams Foster, David." De este último autor, parece que la bibliógrafa mexicana desconoce la segunda edición revisada y aumentada de su Mexican Literature; a Bibliography of Secondary Sources (Metuchen, NJ, 1992), en la cual se agregan unas 250 fichas a las 242 de la primera edición. Ocampo tampoco incluye referencia a las dos primeras bibliografias anotadas sobre Rulfo: Marino Fernández-Cuesta, Juan Rulfo; bibliografia anotada. Tesis doctoral. (The University of New Mexico, 1983); DAI 45, 6 (December, 1984), 1767A-1768A; facsímil xerográfico (Ann Arbor, Michigan, 1991); y Luis Leal, "Selected bibliography," Juan Rulfo (Boston, 1983) 116-125.

${ }^{31}$ Además de citar mal el título de la bibliografía de Estrada, Ocampo se equivoca de las páginas: La mencionada bibliografía ocupa la página 85 y no las páginas 292-293 de Universidad de San Carlos 65 (Guatemala, enero-abril 1965).

${ }^{32}$ Por qué no incluir, por ejemplo — no ya "en vez de," sino "también"- la "Bibliografía crítica sobre Juan Rulfo" que se agrega al estudio de Marcelo Coddou, Valoración de Juan Rulfo (Concepción, 1970) 39-40; repr. Homenaje a Juan Rulfo, Helmy F. Giacoman, editor (Madrid, 1974) 88-89. Esta bibliografía contiene entre sus diecinueve fichas referencias de estudios sobre la obra rulfiana. $Y_{\text {¿por }}$ qué no incluir también algo que dé a conocer el trabajo crítico sobre Rulfo realizado en otros países latinoamericanos y europeos? ¿Por qué no incluir "Fuentes de información sobre Ernesto Sábato, Juan Rulfo, Augusto Roa Bastos, Carlos Droguett," de Alfonso Escudero, Taller de letras 1 (Santiago de Chile, 1971, 110-118 / Juan Rulfo 113-114 (54 fichas)? Y para terminar, ¿por qué no incluir una muestra de los trabajos críticos y bibliográficos realizados en idioma inglés? ¿Por qué no incluir, por ejemplo, la "Selected bibliography" que incluye Luis Leal en Juan Rulfo (Boston, 1983) 116-125una de las mejores y de las primeras anotadas que conocemos.
} 
referencias son mexicanas; un $40 \%$ están tomadas de publicaciones diarias y semanales de México. La inclusión de otros países es, pues, relativamente minúscula.

Gran número de las referencias son difíciles (¿imposibles?) de localizar por ser erróneos, incompletos o poco claros los datos bibliográficos. En primer lugar, la autora utiliza un caótico sistema de siglas que han de frustrar y exasperar al usuario a cada paso. Con frecuencia, la sigla que aparece en la fich a no se incluye en la lista de aclaraciones (886889), o no se corresponde exactamente con la sigla incluida. ${ }^{33}$

Abundantes también son las erratas y descuidadas repeticiones de fichas. AHMAD KHAN, Fareed (899) vuelve rebautizado KHAN, Fareed Ahmed [sic], autor del mismo libro, en la página 925. ANAYA, Margarita se sucede inmediatamente a sí misma, autora de la misma nota en la página 899. El crítico alemán Werner Helwig recibe el apellido HELVING (923). ${ }^{34}$ Otro tanto les pasa a Floyd Merrell: MERREL, Floyd (929) y a Rose S. Minc: MINE, Rose S. (929). ${ }^{35}$ TAGART, K. M. (939) es en realidad Kenneth M. Taggart.

De las omisiones más notables en esta sección mencionaremos solamente cuatro estudios de la obra de Juan Rulfo que nos parece deben incluirse en toda bibliografía sobre el tema: Arno Ros, "Textanalyse der cuentos J. Rulfos," Zur Theorie literarischen Erzählens; mit einer Interpretation der "cuentos" von Juan Rulfo (Frankfurt/M., 1972), 238. /131-223; Luis Leal, Juan Rulfo (Boston, 1983). 132; William Rowe, Rulfo; El Llano en llamas (London, 1987), 84; y Gustavo C. Fares, Imaginar Comala; el espacio en la obra de Juan Rulfo (New York, 1991), 210.

Podríamos seguir apuntando fallas, pero concluiremos con un solo ejemplo representativo - desgraciadamente - de los descuidos que hemos venido exponiendo en estas líneas. En la página 938 se incluye esta ficha bibliográfica:

SAN ADAMS, M. "Handscape and Loss in JR's Pedro Páramo," Chasqui. 1,nov, 1979,pp.24-29.

Corregimos y la ficha reza así:

ADAMS, M. Ian. "Landscape and Loss in Juan Rulfo's Pedro Páramo," Chasqui 9 (1 Nov. 1979), 24-29.

\footnotetext{
${ }^{33}$ De las cincuenta entradas iniciales de la sección de Referecnias (898-900), entresacamos los siguientes ejemplos de siglas no incluidas en las aclaraciones: La CD, MA, RL, El SC, El SMC, TC, EI UC; y de las siglas que no tienen correspondencia exacta en la lista de aclaraciones, estos ejemplos: La CM (¿será La C. en M. de la lista?); DC (¿D. de la C.?); El HC (¿El H. C.?); Rev. MC (¿Rev. M.

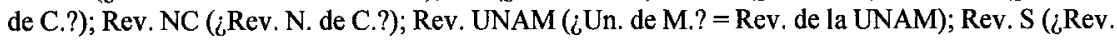
de la S?). En la lista de siglas el nombre del suplemento dominical de Excélsior reza "Diograma [sic] de la cultura" cuando debe decir "Diorama de la cultura."

${ }^{34}$ El título correcto de su reseña es "Mexikanischer Orpheus" y no "Pedro Páramo."

${ }^{35}$ El título correcto del trabajo de Merrell es "Multiple images of death ...," y no "Multiples images of death ...."
} 


\section{Filmografia de Juan Rulfo}

Al cuidado de Sergio López Mena, la "Filmografía" presenta el inventario de Jorge Ayala Blanco incluido en la reimpresión de $1990 \mathrm{de}$ El gallo de oroy otros textos paracine..$^{36}$ De las quince películas, nueve conservan el mismo título de la obra rulfiana. Las restantes son adaptaciones retituladas o films en que actuó o colaboró Juan Rulfo.

Hemos destacado algunas deficiencias del volumen en el curso de esta nota. Otros ejemplos: La "Introducción del Coordinador" adolece de las siguientes erratas e incorrecciones: Cuatro veces se escribe "jaliscience" por "jalisciense" (xxi, xxix, xxx); "parsimonia" se escribe "parcimonia" (xxiv); el Coordinador llama Báez de Jiménez a una de los colaboradores del volumen, la escritora Yvette Jiménez de Báez (xxviii, dos veces). Y en nota al pie de la página xxiv, se cita el título rulfiano, "Tres cartas a Clara", el mismo que aparece citado en la Bibliografía con el título "Dos cartas a Clara" (896).

Diremos para concluir esta nota que a nuestro parecer la concienzuda labor de investigación realizada por Sergio López Mena es la que reivindica Juan Rulfo; toda la obra. La "Nota filológica preliminar" de este estudioso, con la edición crítica de los textos de El Llano en llamas y Pedro Páramo, que suman unas 320 páginas - la tercera parte del total - constituyen, creemos, la contribución más valiosa y original que ofrecen las páginas de este volumen. Lo demás no llega a la misma altura y deja amplio lugar para mejoras significativas en futuras ediciones.

El lector sospecha desde un principio - y el paciente examen del volumen tristemente lo confirma- que esta edición simplemente no recibió de parte de los responsables toda la atención que merecía la inmensa obra pequeña de Juan Rulfo. ${ }^{37}$

\footnotetext{
${ }^{36}$ No hemos visto la reimpresión de que procede el presente inventario. La que manejamos es de 1986. Confrontando las dos reimpresiones, observamos que la más reciente agrega cuatro títulos. El inventario de 1990 incluye las siguientes películas: Talpa (1955); El despojo (1960); Paloma herida (1962, argumento de Juan Rulfo); El gallo de oro (1964); La fórmula secreta (1964); En este pueblo no hay ladrones (1964, cuento de García Márquez, actuación de Juan Rulfo); Pedro Páramo (1966); El rincón de las virgenes (1972, argumento de Juan Rulfo basado en "Anacleto Morones" y "El día del derrumbe"); ¿No oyes ladrar los perros? / N'entends-tu pas les Chiens aboyer? (mexicanofrancés, 1974, título así con signos de interrogación); Pedro Páramo; el hombre de la Media Luna (1970); El hombre (1978). Las adiciones a la lista de 1986 son: Que esperen los viejos (1976, basado en textos — sin detallar- de Juan Rulfo); Talpa (1982); Tras el horizonte (1984, argumento basado en E1 hombre); El imperio de la fortuna (1986, argumento basado en "El gallo de oro").

${ }^{37}$ Escritas estas líneas, llega a nuestra atención la siguiente noticia: Ya programada la publicación del presente volumen, el director original, Carlos Montemayor, abandonó el proyecto, suplantándolo Claude Fell para rescatar la edición a última hora. El dato explica algunas de las deficiencias que hemos detallado en el curso de nuestra nota.
} 
